\title{
Re-evaluation of paleo-accumulation parameterization over Northern Hemisphere ice sheets during the ice age examined with a high-resolution AGCM and a 3-D ice-sheet model
}

\author{
Takateru YAMAGISHI, ${ }^{1}$ Ayako ABE-OUCHI, ${ }^{1,2}$ Fuyuki SAITO, ${ }^{2}$ \\ Tomonori SEGAWA, ${ }^{2}$ Teruyuki NISHIMURA ${ }^{2}$ \\ ${ }^{1}$ Center for Climate System Research, The University of Tokyo, Kashiwanoha 5-1-5, Kashiwa, Chiba 277-8568, Japan
E-mail: takateru@Ccsr.u-tokyo.ac.jp
${ }^{2}$ Frontier Research Center for Global Change, 3173-25 Showa-machi, Kanazawa-ku, Yokohama 236-0001, Japan
}

\begin{abstract}
Simulations of the Northern Hemisphere ice sheet at the Last Glacial Maximum (LGM; $21 \mathrm{kyr} B P$ ) are performed using a high-resolution atmospheric general circulation model (AGCM) in order to re-evaluate the conventional surface temperature- or elevation-based parameterization. The influence of precipitation change on the steady-state topography of the Laurentide ice sheet at the LGM is estimated using an AGCM with a horizontal resolution of $\sim 1^{\circ}$ and a three-dimensional thermomechanically coupled ice-sheet model. The ice volume estimated by the AGCM simulation is much larger than that indicated by the conventional parameterization. Through sensitivity analysis of the AGCM and ice-sheet model, it is found that the rate of precipitation change depends on the location of the ice sheet, and that the rate of precipitation change due to surface elevation change is higher than the rate unrelated to surface elevation change on the Laurentide ice sheet. The rate of precipitation is also shown to exhibit seasonality and regionality due to effects such as interior desertification and the concentration of storm tracks.
\end{abstract}

\section{INTRODUCTION}

Precipitation is an important process in the interaction between ice sheets and the atmosphere. In general, precipitation is related to surface elevation as a result of changes in the water-holding capacity of the atmosphere. Precipitation has been related to surface temperature by a parameterization with coefficients determined by ice-core analyses (Yiou and others, 1985; Clausen and others, 1988; Huybrechts and T'siobbel, 1995), and this parameterization has been used in a number of studies to simulate the distribution of ice sheets at the Last Glacial Maximum (LGM; $21 \mathrm{kyr}$ ) and/or ice-age cycles (Huybrechts and T'siobbel, 1995; Peltier and Marshall, 1995; Ritz and others, 1997; Tarasov and Peltier, 1997; Greve and others, 1999; Cuffey and Marshall, 2000). In those studies, it was assumed that the pattern of precipitation was the same as at present, with a simple modification proportional to the change in surface temperature or sea-level temperature estimated from icecore data or a snapshot result from an energy-balance model. As the conventional parameterization is defined in reference to surface temperature or sea-level temperature, it has a low computational cost compared to the atmospheric general circulation model (AGCM) and as such is suitable for the simulation of ice sheets at long timescales.

However, the change in local temperature is not the only factor determining a change in precipitation. The atmosphere is also affected by the topography of the ice sheets themselves (Hall and others, 1996; Kageyama and Valdes, 2000; Vettoretti and others, 2000). Precipitation increases on the windward side of ice sheets due to the ascent of air up the slopes, resulting in desertification of the interior of the ice sheets. Budd and Smith (1981) parameterized the interior desertification effect based on surface elevation, and Tarasov and Peltier (2004) indicated that interior desertification on the Laurentide ice sheet is necessary in order to fit relative sea-level observations. Ritz and others (1997) and Cuffey and Marshall (2000) considered orographically driven precipitation by the ascent of air at the margins of Greenland based on estimations from the changes in ice surface slopes. The change in large-scale atmospheric circulation, which cannot be expressed by local changes in surface slopes, also influences precipitation, where the topography of the ice sheets alters stationary waves and causes the concentration and shifting of transient eddies. The increase in precipitation due to the change in transient eddies may in fact have promoted the southward growth of the Laurentide ice sheet (Broccoli and Manabe, 1987).

A range of physical processes have also been shown to affect precipitation. Krinner and Genthon (1999) evaluated the dependence of precipitation on surface temperature in Greenland through an AGCM experiment, and Sanberg and Oerlemans (1983) and Roe and Lindzen (2001) estimated the precipitation on an ice sheet based on the temporalmean wind and temperature field. In the present study, the change in precipitation due to changes in ice-sheet topography is examined for several types of ice sheets based on AGCM experiments performed at higher resolution (T106, $\sim 1^{\circ}$ ) than in previous studies. The changes are compared with other parameters such as albedo, $\mathrm{CO}_{2}$, sea surface temperature (SST) and insolation. Consistent with previous studies, the results are parameterized in terms of surface temperature change, which can be estimated from the icesheet topography based on an assumed lapse rate.

Another consideration is the influence of precipitation on the response of the ice sheet through the effect of surface mass balance. Roe (2002) studied the change in the Greenland ice sheet with a range of parameterizations of precipitation using a three-dimensional (3-D) ice-sheet model. Fabre and others (1998), Pollard and others (2000), Charbit and others (2002), 
Table 1. Boundary conditions for AGCM experiments. P: present, L: Last Glacial Maximum

\begin{tabular}{lcccc}
\hline Experiment & CNTL & NO & FLAT & FULL \\
\hline SST & P & $\mathrm{L}$ & $\mathrm{L}$ & $\mathrm{L}$ \\
Insolation & $\mathrm{P}$ & $\mathrm{L}$ & $\mathrm{L}$ & $\mathrm{L}$ \\
$\mathrm{CO}_{2}$ & $\mathrm{P}$ & $\mathrm{L}$ & $\mathrm{L}$ & $\mathrm{L}$ \\
Albedo & $\mathrm{P}$ & $\mathrm{P}$ & $\mathrm{L}$ & $\mathrm{L}$ \\
Ice sheets & $\mathrm{P}$ & $\mathrm{P}$ & $\mathrm{P}$ & $\mathrm{L}$ \\
& & & & \\
\hline
\end{tabular}

Marshall and others (2002) and Zweck and Huybrechts (2003) evaluated the response of the Northern Hemisphere ice sheets to the precipitation modeled by AGCMs. That parameterization is re-evaluated in this study through AGCM sensitivity experiments with high horizontal resolution using a 3-D thermomechanical ice-sheet model (Saito, 2002; Saito and Abe-Ouchi, 2004). The influence of the change in precipitation estimated from the AGCM on the steady-state topography of the Laurentide ice sheet is also examined.

\section{EXPERIMENTS}

In the present study, separate models are used for the atmospheric experiment and the ice-sheet experiment. A CCSR/NIES AGCM (Numaguti and others, 1997) is used to evaluate the change in precipitation in response to ice-sheet topography. To resolve precipitation on a regional scale, the resolution of the AGCM is set to T106 horizontally $\left(\sim 1^{\circ}\right.$ latitude and longitude) and 20 levels are defined vertically.

Four numerical experiments were carried out assuming different boundary conditions (CNTL, NO, FLAT and FULL), as listed in Table 1. CNTL and FULL are based on the Paleoclimate Modelling Intercomparison Project (PMIP; Joussaume and Taylor, 1995), where CNTL represents a present-day control simulation and FULL is the LGM experiment. CLIMAP (CLIMAP Project Members, 1981) is used for the SST, Peltier (1994) is employed for ice-sheet topography, insolation parameters are set at the LGM values, and $\mathrm{CO}_{2}$ concentration is set at $200 \mathrm{ppm}$. FLAT is a sensitivity experiment conducted for orography of the Northern Hemisphere ice sheet, where the ice sheet covers the same area as in FULL but the thickness is set to $0 \mathrm{~m}$ except for Greenland (present). The distribution of surface albedo and other parameters is set the same as in FULL. The ice sheet and SST in the NO experiment are the same as in CNTL, while $\mathrm{CO}_{2}$ and insolation parameters are set the same as in FULL. Each experiment runs for 11 or 13 model years, and the results for the last 10 years are analyzed. Computation speed for experiments was about 40 days per 10 model years on an NEC SX-5 with a single processor. The difference between the FULL and FLAT experiments therefore represents the effect of ice-sheet topography, the difference between the FLAT and $\mathrm{NO}$ experiments represents the effect of the albedo of the ice sheets, and the difference between $\mathrm{NO}$ and CNTL represents the effect of $\mathrm{CO}_{2}$, SST and insolation.

The Laurentide ice sheet at the LGM is also simulated using a 3-D thermomechanical ice-sheet model in order to estimate the influence of the change in precipitation on the ice-sheet distribution. The ice-sheet model used in the present paper is a standard 3-D shallow-ice approximation model (Saito, 2002; Saito and Abe-Ouchi, 2004) reprojected on a spherical grid system. The ice-sheet model assumes ice as a non-Newtonian viscous fluid with Glen's flow-law exponent of 3 . The thickness, velocity and temperature distribution of the ice sheet are calculated under a prescribed climate condition defined in terms of surface mass balance and temperature. The dynamics of the ice shelf and the grounding line are not included in the model; instead, Hudson Bay is treated as land toward which the ice sheet is allowed to advance. The ice enhancement factor is set at 3, and a constant value of $42 \mathrm{~mW} \mathrm{~m}^{-2}$ is set for the geothermal heat flux. For basal sliding, the linear parameterization presented in Marshall and others (2002) is applied with a coefficient of $0.01 \mathrm{~m} \mathrm{a}^{-1} \mathrm{~Pa}^{-1}$. The bedrock boundary condition is derived from the ETOPO5 dataset (NGDC, 1988). A positive-degree-day method is applied for parameterization of surface mass balance, with melt factors for snow and ice of 3.0 and $8.0 \mathrm{~mm}$ w.e. ${ }^{\circ} \mathrm{C}^{-1} \mathrm{~d}^{-1}$ and a snow refreezing fraction of 0.6 (Jóhannesson and others, 1995). The horizontal resolution of the model is $0.5^{\circ}$, and the vertical resolution is 26 levels. The time-step for solving the evolution of thickness and thermodynamics is 1 year, and all experiments were run for $80 \mathrm{kyr}$ to reach a steady state. Although the Laurentide ice sheet at the LGM is unlikely to have reached such a steady state, the present experiments were designed to reveal the fundamental character of the influence of precipitation on the Laurentide ice sheet.

\section{ANALYSIS OF PRECIPITATION IN AGCM EXPERIMENTS}

Figure 1a shows the change in precipitation between CNTL and FULL. The high-resolution AGCM successfully simulates the increase in precipitation from the southeastern margin of the Laurentide ice sheet to western Europe due to the concentration of storm tracks (Hall and others, 1996; Kageyama and Valdes, 2000; Vettoretti and others, 2000). The difference also successfully reproduces the decrease in precipitation over the Greenland ice sheet at the LGM (a twothirds reduction on present levels based on ice-core data; Dansgaard and others, 1993). Figure $1 \mathrm{~b}$ shows the cumulative effect of SST, $\mathrm{CO}_{2}$ and insolation change at the LGM (difference between CNTL and NO). At mid-latitudes, the effect of SST cooling results in a zonal asymmetric change in surface temperature and a change in the pattern of stationary waves and transient eddies, leading to a change in precipitation. Figure 1c shows the albedo effect (difference between $\mathrm{NO}$ and FLAT). Again, the reduction in albedo gives rise to a change in the pattern of stationary waves, leading to a strengthening of the wet westerly wind from the Pacific to the southwestern area of the Laurentide ice sheet, and increased precipitation. Precipitation decreases over the rest of the ice sheets due to the decrease in the water-holding capacity of the atmosphere as a result of surface cooling. Figure $1 \mathrm{~d}$ shows the effect of ice-sheet topography (difference between FLAT and FULL). On the windward side of the ice sheets, precipitation increases due to the effect of up-slope rise, which in combination with overall cooling results in desertification of the interior of the Laurentide ice sheet. Precipitation increases in the southeast of the Laurentide ice sheet due to the concentration of transient eddies associated with the change in the stationary waves due to ice-sheet topography.

Figure 2 shows a comparison of each effect on each ice sheet at the LGM. The largest decrease in precipitation (CNTL-FULL) occurs over Greenland, with a decrease of 

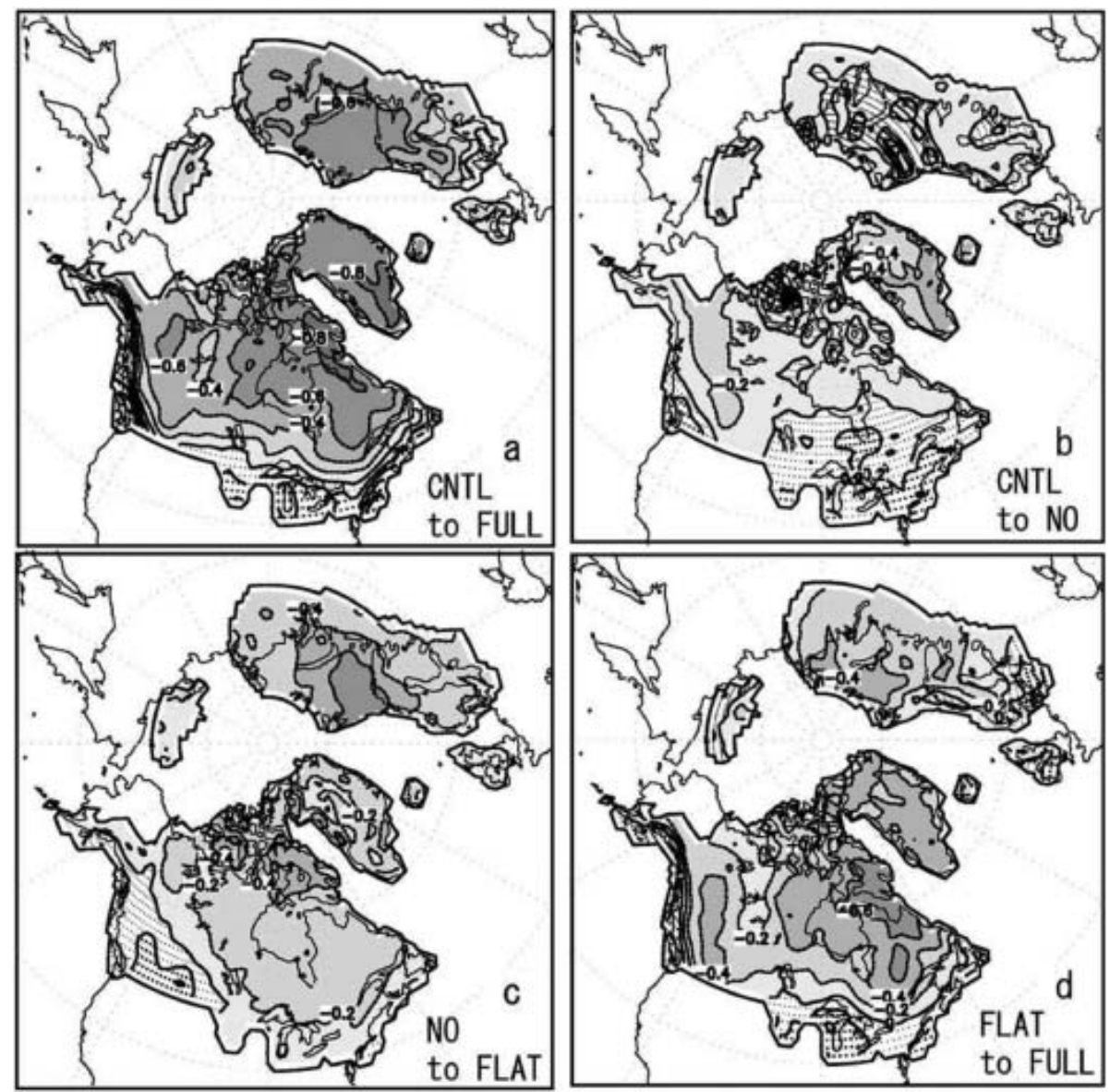

Fig. 1. Fractional change in precipitation from (a) CNTL to FULL, (b) CNTL to NO, (c) NO to FLAT, and (d) FLAT to FULL. The first of the compared experiments is used as the denominator for calculating the ratio (e.g. (a) denotes $\left.\left(\mathrm{PRE}_{\mathrm{FULL}}-\mathrm{PRE}_{\mathrm{CNTL}}\right) / \mathrm{PRE} \mathrm{CNTL}_{\mathrm{C}}\right)$. Contour interval is 0.2. Negative values are shaded, and positive values are dotted.

about $75 \%$. This decrease is not typical of the Northern Hemisphere, and the use of ice-core data for Greenland to estimate the precipitation change over the entire region of the Northern Hemisphere in the ice-age cycles may therefore result in an underestimation of precipitation for other ice sheets. The precipitation change estimated by the Clausius-Clapeyron (C-C) equation, assuming saturated air and proportionality between precipitation and the change in the saturated air mass, is also shown in the figure. The total LGM effect estimated by the C-C equation indicates a larger decrease than that by the AGCM, and the dependence on the location of the ice sheet is not as strong as in the AGCM.

Figure $3 \mathrm{a}$ shows the relationship between the ratio of annual mean precipitation change between CNTL and FULL and the annual mean surface temperature change between CNTL and FULL on the Laurentide ice sheet. Two clusters of positive ratio can be seen, where the right cluster corresponds to the increase in precipitation on the windward side of the Rockies due to topographic effects, and the left cluster corresponds to the increase in precipitation in the southeast of the Laurentide ice sheet due to the concentration of storm tracks. For comparison with previous studies, the ratio of precipitation change was parameterized against the annual mean surface temperature. The effect of seasonal change is discussed later. The least-squares regression coefficient for the present model is $2.5 \% \mathrm{~K}^{-1}$ (black line in Fig. 3a), lower than that by the conventional parameterizations (e.g. $3 \% \mathrm{~K}^{-1}$ by Tarasov and Peltier (1997) and $4 \% \mathrm{~K}^{-1}$ by Huybrechts and T'siobbel (1995)), which are based on ice-core data for other ice sheets (e.g. Greenland and Antarctica). The $2.5 \% \mathrm{~K}^{-1}$ rate reflects the smaller precipitation change on the Laurentide ice sheet compared to other ice sheets (Fig. 2), as revealed by the AGCM experiments. The relationship between the surface temperature change and the precipitation change estimated by the $C-C$ equation assuming a saturated air mass is also shown in the figure. A large decrease in precipitation and strong dependence on surface temperature can be seen, with a regression coefficient of $8.0 \% \mathrm{~K}^{-1}$ (green line in Fig. 3a). This result is much higher than the rate indicated by the difference between CNTL and FULL, and may therefore lead to an underestimation of precipitation.

Figure $3 \mathrm{~b}$ and c show the relationship between the ratio of annual mean precipitation change and the annual mean surface temperature change on the Laurentide ice sheets (CNTL-NO, NO-FLAT, FLAT-FULL). Table 2 shows the regression coefficient for the parameterization of the ratio of precipitation change against the annual mean surface temperature and the variance of the residuals from a leastsquares regression curve. The coefficient for the effect of icesheet topography (Fig. $3 \mathrm{c} ; 5.3 \% \mathrm{~K}^{-1}$ ) is larger than the other two effects (Fig. $3 \mathrm{~b} ; 2.2 \% \mathrm{~K}^{-1}$ and $2.0 \% \mathrm{~K}^{-1}$ ), attributable to the effect of interior desertification. In the present parameterization, the effect of ice-sheet topography is separated from other effects, as it imparts a larger influence on atmospheric circulation change (e.g. interior desertification, concentration of storm tracks). The regression coefficient for the combination of the two other effects (CNTL-FLAT) is estimated by the same method to be $1.7 \% \mathrm{~K}^{-1}$, which again 


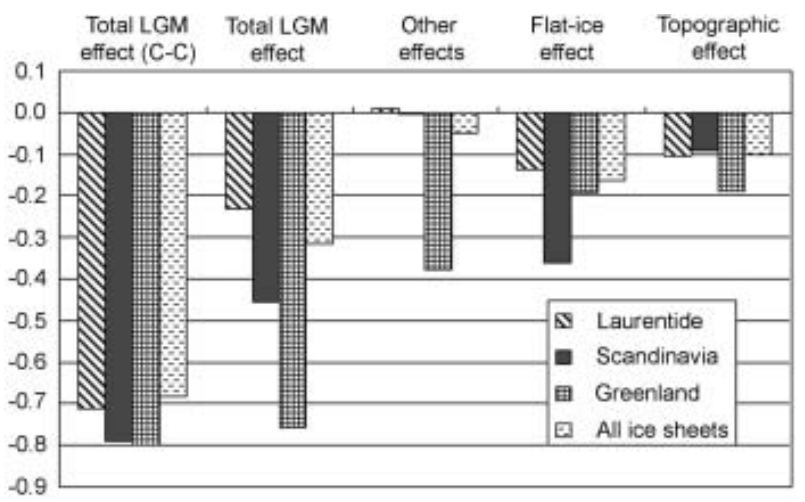

Fig. 2. Ratio between the change in area-averaged precipitation and the precipitation obtained by the CNTL experiment. The changes in precipitation are estimated by the AGCM or the C-C equation. Results are shown for the Laurentide, Scandinavian and Greenland ice sheets and the total. Total LGM (C-C): change from CNTL to FULL estimated by the C-C equation. Total LGM: change from CNTL to FULL. Other: change from CNTL to NO. Flat ice: change from CNTL to FLAT. Topographic: change from FLAT to FULL.

is lower than that determined in previous studies (e.g. $3 \% \mathrm{~K}^{-1}$ by Tarasov and Peltier (1997) and $4 \% \mathrm{~K}^{-1}$ by Huybrechts and T'siobbel (1995)). However, the ratios of change derived in previous studies are based on ice-core data obtained from interior sites and are therefore confounded by the effect of interior desertification. Table 2 shows the variance of residuals from the regression curve, and the effects of the scatter of the CNTL to FLAT and FLAT to FULL are discussed later.

\section{EFFECT OF PRECIPITATION ON THE STEADY-STATE LAURENTIDE ICE SHEET}

The effect of precipitation on the steady-state Laurentide ice sheet was determined by integrating the 3-D ice-sheet model until the ice sheet reached an equilibrium state. The initial condition was defined as the absence of an ice sheet. The surface air temperature (SAT) was set according to

$$
\mathrm{SAT}=\mathrm{SAT}_{\text {present }}+\left(\mathrm{SAT}_{\text {full }}-\mathrm{SAT}_{\text {cntl }}\right)+\text { lap } \mathrm{d} h .
$$

The perturbation calculated by the AGCM was then added to the present climatology (re-analyzed European Centre for Medium-Range Weather Forecasts data), and modified by the growth of the ice sheet $(\mathrm{d} h)$ by setting a lapse rate (lap) of $-5.0 \mathrm{~K} \mathrm{~km}^{-1}$.

The parameterization of precipitation (PRE), modifying the present precipitation, was expressed in terms of the two effects (topography and general climatic cooling) as follows:

$$
\begin{array}{r}
\text { PRE }=\text { PRE }_{\text {present }}\left[\left(1+f_{1}\right)^{\text {SATflat }- \text { SATcntl }}+\text { Dev }_{1}\right] \\
\cdot\left[\left(1+f_{2}\right)^{\text {lap d } h}+\operatorname{Dev}_{2}\right] .
\end{array}
$$
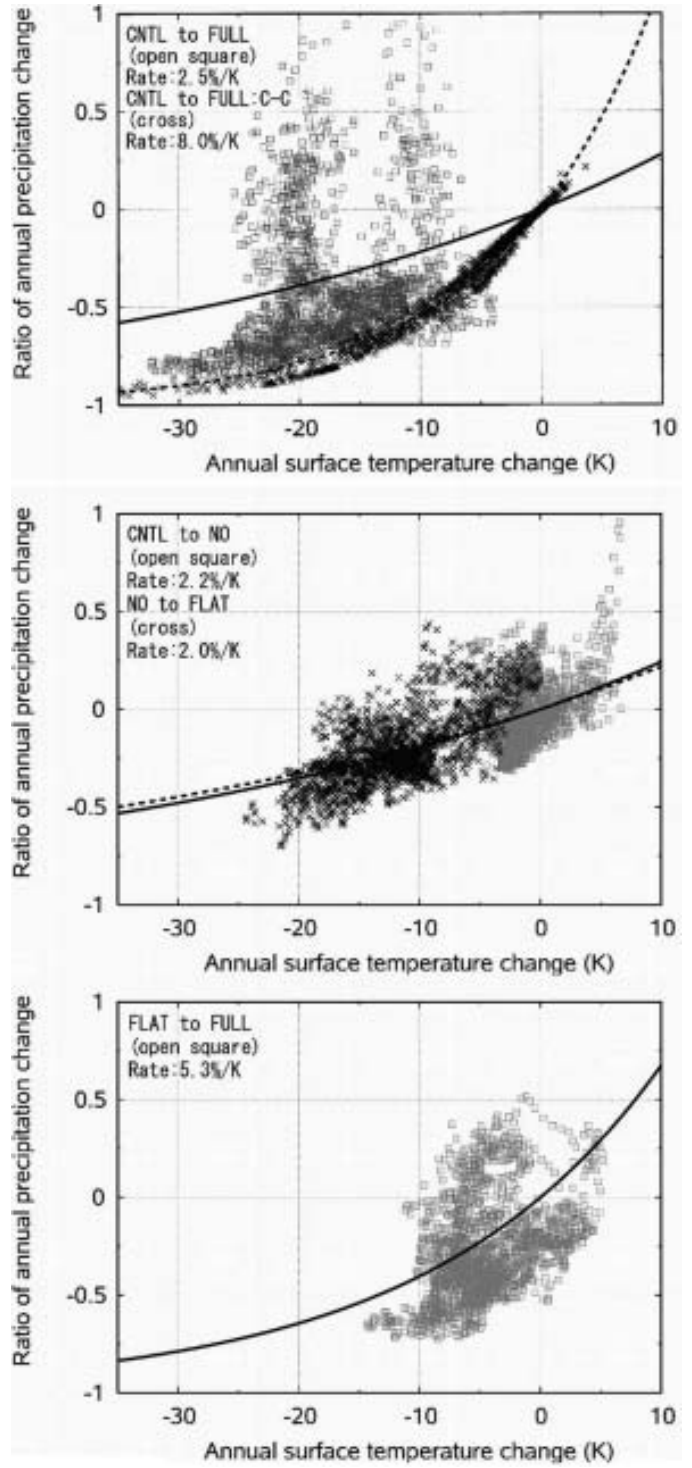

Fig. 3. Scatter diagrams of the change in annual mean surface temperature difference vs the change in annual mean precipitation rate on the Laurentide ice sheet for change from (a) CNTL to FULL (open square and solid regression line) and CNTL to FULL by C-C (cross and dashed regression line); (b) CNTL to NO (open square and solid regression line) and NO to FLAT (cross and dashed regression line); and (c) FLAT to FULL (open square and solid regression line).

In this experiment, CMAP (Xie and Arkin, 1996) was used as the present reference precipitation. The factors $f_{1}$ and $f_{2}$ are the rate of precipitation change due to surface temperature between CNTL and FLAT, and between FLAT and FULL, respectively (Table 2). The terms $\operatorname{Dev}_{1}$ and $\operatorname{Dev}_{2}$ represent the deviation from the regression curve for the change from CNTL to FLAT and from FLAT to FULL, respectively.

Table 2. The rate of annual precipitation change by each effect, estimated by a method of least squares, and the variance of residuals from the regression curve

\begin{tabular}{lccccc}
\hline & CNTL to FULL & CNTL to NO & NO to FLAT & FLAT to FULL \\
\hline Rate & $2.5 \% \mathrm{~K}^{-1}$ & $2.2 \% \mathrm{~K}^{-1}$ & $2.0 \% \mathrm{~K}^{-1}$ & 0.0219 & $5.3 \% \mathrm{~K}^{-1}$ \\
Variance of residuals & 0.1353 & 0.0252 & $\begin{array}{c}1.7 \% \mathrm{~K}^{-1} \\
0.0440\end{array}$ & 0.0634 & 0.040 \\
\hline
\end{tabular}


Table 3. Experiment design together with the result of ice-sheet model experiment (Exp 1-8). Exp 1-8 except Exp3 adopt Equation (1) and set the present precipitation (CMAP) as the reference. Exp 3 adopts Equation (2) and sets the precipitation of the AGCM experiment. The terms $f_{1}, f_{2}, \operatorname{Dev}_{1}$ and $\operatorname{Dev}_{2}$ correspond to Equation (1). Exp3 and Exp8 consider the seasonal change (*; see Fig. 8) of $f_{1}$ and $f_{2}$. Volume and maximum surface height of the simulated Laurentide ice sheet for each experiment are shown. The values in parentheses denote the percentage differences from Exp3, which is based on the AGCM experiment

\begin{tabular}{|c|c|c|c|c|c|c|c|c|}
\hline & Reference & $\begin{array}{l}f_{1} \\
\%\end{array}$ & $\begin{array}{l}f_{2} \\
\%\end{array}$ & $\operatorname{Dev}_{1}$ & $\operatorname{Dev}_{2}$ & $\begin{array}{l}\text { Volume } \\
10^{7} \mathrm{~km}^{-3}\end{array}$ & $\begin{array}{c}\text { Max. height } \\
\text { km }\end{array}$ & Description \\
\hline Exp1 & PRESENT & 2.5 & 2.5 & No & No & $4.23(-5 \%)$ & $3.86(-7 \%)$ & Total effect on the Laurentide \\
\hline Exp2 & PRESENT & - & - & - & - & $4.60(+3 \%)$ & $3.77(-9 \%)$ & Budd and Smith (1981) \\
\hline Exp3 & AGCM & - & $* 5.3$ & - & - & $4.47(0 \%)$ & $4.14(0 \%)$ & AGCM result with seasonal change \\
\hline Exp4 & PRESENT & 1.7 & 5.3 & No & No & $4.06(-9 \%)$ & $3.62(-13 \%)$ & The rates of the two effects \\
\hline Exp5 & PRESENT & 1.7 & 5.3 & Yes & No & $4.07(-9 \%)$ & $3.70(-11 \%)$ & Exp4 with Dev 1 \\
\hline Exp6 & PRESENT & 1.7 & 5.3 & No & Yes & $4.08(-9 \%)$ & $3.81(-8 \%)$ & Exp4 with $\mathrm{Dev}_{2}$ \\
\hline Exp7 & PRESENT & 1.7 & 5.3 & Yes & Yes & $4.10(-8 \%)$ & $3.93(-5 \%)$ & Exp4 with $\operatorname{Dev}_{1}$ and $\operatorname{Dev}_{2}$ \\
\hline Exp8 & PRESENT & *1.7 & $* 5.3$ & No & No & $4.49(0 \%)$ & $3.98(-4 \%)$ & Exp4 with seasonal change \\
\hline
\end{tabular}

If the snapshot result of an AGCM is available, it is modified by the effect of ice-sheet topography as follows.

$$
\mathrm{PRE}=\mathrm{PRE}_{\text {present }} \frac{\mathrm{PRE}_{\mathrm{AGCM}}}{\operatorname{PRE}_{\mathrm{CNTL}}}\left(1+f_{2}\right)^{\text {lap } \mathrm{d} h} .
$$

In the present experiments, $\mathrm{d} h$ represents the deviation of the surface height from the reference topography (Peltier, 1994) of the FULL experiment. Dev ${ }_{1}$ and $\operatorname{Dev}_{2}$ are included in Equation (3) because the deviational component is expressed by an AGCM. By distinguishing the two rates $\left(f_{1}\right.$ and $\left.f_{2}\right)$, the modeled precipitation can be modified in consideration of the effect of ice-sheet topography.

Three simulations of the steady-state Laurentide ice sheet were carried out (Exp1-Exp3 in Table 3). Exp1 modifies the reference present precipitation by Equation (2), adopting the $2.5 \% \mathrm{~K}^{-1}$ rate for both $f_{1}$ and $f_{2}$ without deviational components $\left(\operatorname{Dev}_{1}\right.$ and $\left.\operatorname{Dev}_{2}\right)$. Exp2 adopts the 'elevationdesert' effect proposed by Budd and Smith (1981), whereby the precipitation decreases from a reference value by a factor of 2 for each kilometer of ice thickness $(Z)$ above the $2 \mathrm{~km}$ elevation $(E)$, as given by

$$
\mathrm{PRE}=\frac{\mathrm{PRE}_{\text {present }}}{2^{E-2}}
$$

If the bed is already above $2 \mathrm{~km}, \mathrm{PRE}$ is given by

$$
\mathrm{PRE}=\frac{\mathrm{PRE}_{\text {present }}}{2^{Z}}
$$

Exp3 uses the precipitation given by the AGCM experiment, which is a modification of the monthly rate due to the topographic effect (Figs 4 and 8). The maximum surface height in Exp2 is $2 \%$ lower than that in Exp1 due to the
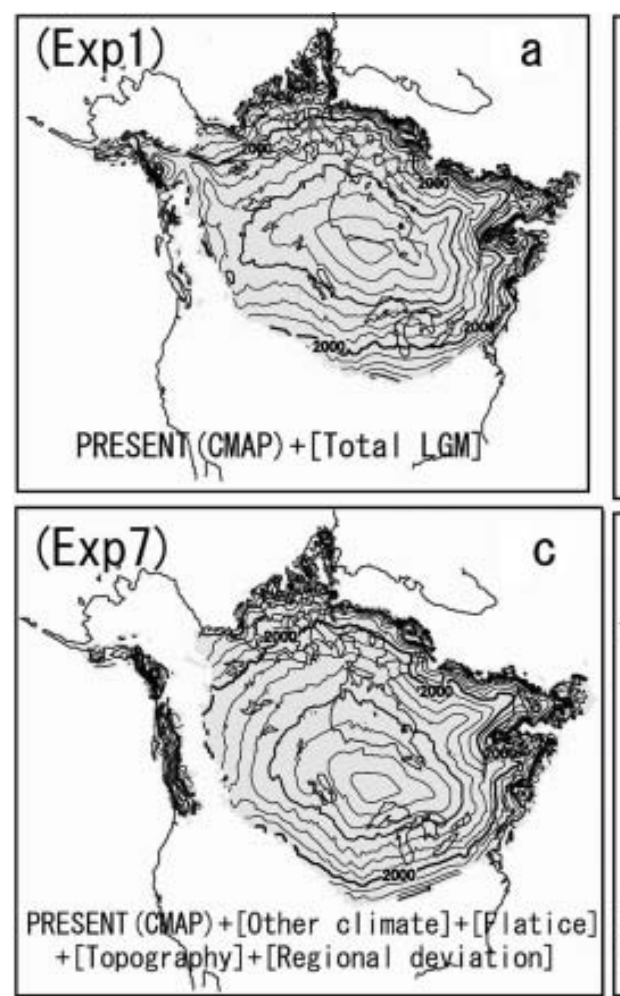
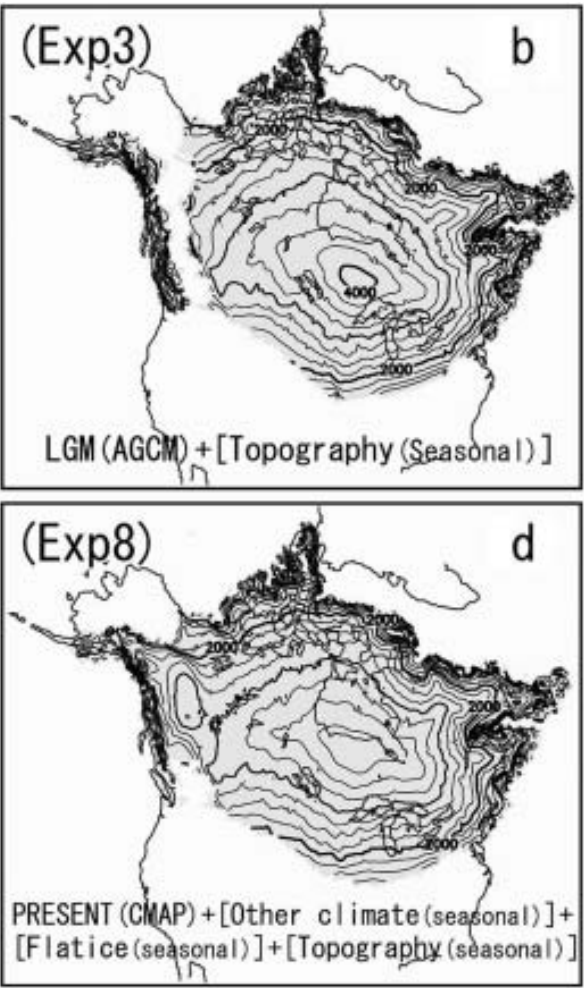

Fig. 4. Steady-state Laurentide ice sheet surface topography by (a) Exp1, (b) Exp3, (c) Exp7 and (d) Exp8 (contour interval 250 m). 


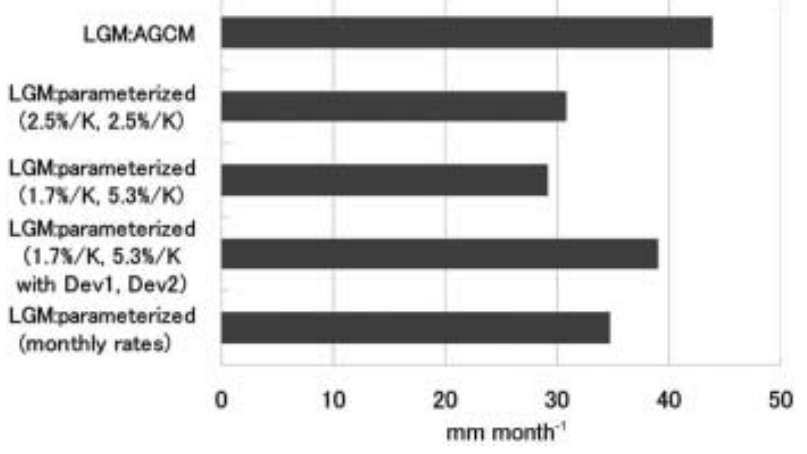

Fig. 5. Simulated and present observed annual precipitation $\left(\mathrm{mm} \mathrm{month}^{-1}\right.$ ) (CMAP; Xie and Arkin, 1996) averaged over the Laurentide ice sheet, showing parameterization and AGCM results (surface temperature calculated using ice-sheet surface at the LGM; Peltier, 1994).

strong desertification effect $\left(>2.5 \% \mathrm{~K}^{-1}\right)$. However, the steady-state volume of Exp2 is $8 \%$ higher than that of Exp1, as the desertification effect does not act on the lower surface. Figure 1d shows that the precipitation decreases in most of the area where the change in surface elevation is $<2 \mathrm{~km}$, suggesting that the desertification effect should also apply to lower surfaces. The steady-state volume of the Laurentide ice sheet in Exp1 is 5\% lower than in Exp3, and the maximum surface height is $7 \%$ lower. From Figure 5, which shows the simulated annual precipitation averaged over the Laurentide ice sheet, the precipitation in Exp1 is about $30 \%$ lower than in Exp3, leading to the underestimation of volume and maximum surface height for the steady-state Laurentide ice sheet. The factors causing these differences in precipitation, ice-sheet volume and maximum surface height are discussed in the next section.

\section{FACTORS CONTRIBUTING TO THE DIFFERENCE BETWEEN THE AGCM AND THE CONVENTIONAL PARAMETERIZATION}

Three factors can be identified as contributing to the difference between the AGCM and the conventional parameterization. The first is the effect of interior desertifica- tion. From the present AGCM experiments, the rate of precipitation change due to surface elevation change is $5.3 \% \mathrm{~K}^{-1}$, which is much larger than the rate determined unrelated to surface elevation change $\left(1.7 \% \mathrm{~K}^{-1}\right)$. In Exp4, the present precipitation is modified by Equation (2), which adopts both rates $\left(1.7 \% \mathrm{~K}^{-1}\right.$ and $\left.5.3 \% \mathrm{~K}^{-1}\right)$. However, the difference between the AGCM and the conventional parameterization is even larger in the case of Exp4. The ice volume and maximum surface height in Exp4 are lower than those in Exp1 because of the stronger interior desertification effect in Exp4. Furthermore, even taking the two rates based on the AGCM sensitivity experiments, the annual precipitation averaged over the Laurentide ice sheet is much lower than that of the AGCM FULL experiment (Fig. 5).

The second factor is the regional variation in the rate of precipitation change (e.g. in areas of interior desertification or concentration of storm tracks) over the Laurentide ice sheet. Figure $6 \mathrm{a}$ and $\mathrm{b}$ show the deviation from the regression curve of the change between CNTL and FLAT (i.e. $1.7 \% \mathrm{~K}^{-1}$ ) and between FLAT and FULL (i.e. $5.3 \% \mathrm{~K}^{-1}$ ). The variance of the residuals for the topographic effect (FLAT/FULL) is larger than that for the other effects (CNTL/ FLAT) (Table 2), due to the effects of interior desertification and the concentration of storm tracks on the Laurentide ice sheet. Thus, without considering the regional variation in the rate of precipitation change, the rate becomes smaller in the south of the Laurentide ice sheet where precipitation is higher than in the northern area. Figure 5 shows that the area-averaged precipitation increases when the regional variation is considered $\left(\operatorname{Dev}_{1}\right.$ and $\left.\mathrm{Dev}_{2}\right)$. In terms of simulated volume, the experiments considering the deviational component (Exp5-7) do not differ appreciably from Exp4. However, differences can be seen between the experiments in terms of surface topography. Figure $7 \mathrm{a}$ and b show the variation in the steady-state surface topography of the Laurentide ice sheet due to these deviational components. The effect of the deviational component due to ice-sheet topography $\left(\operatorname{Dev}_{2}\right)$ is stronger than that due to other effects $\left(\operatorname{Dev}_{1}\right)$, reflecting the difference seen in the variance of residuals (Table 2). The effects of regional variation become significant when the advancement and maintenance of the Laurentide ice sheet are discussed.

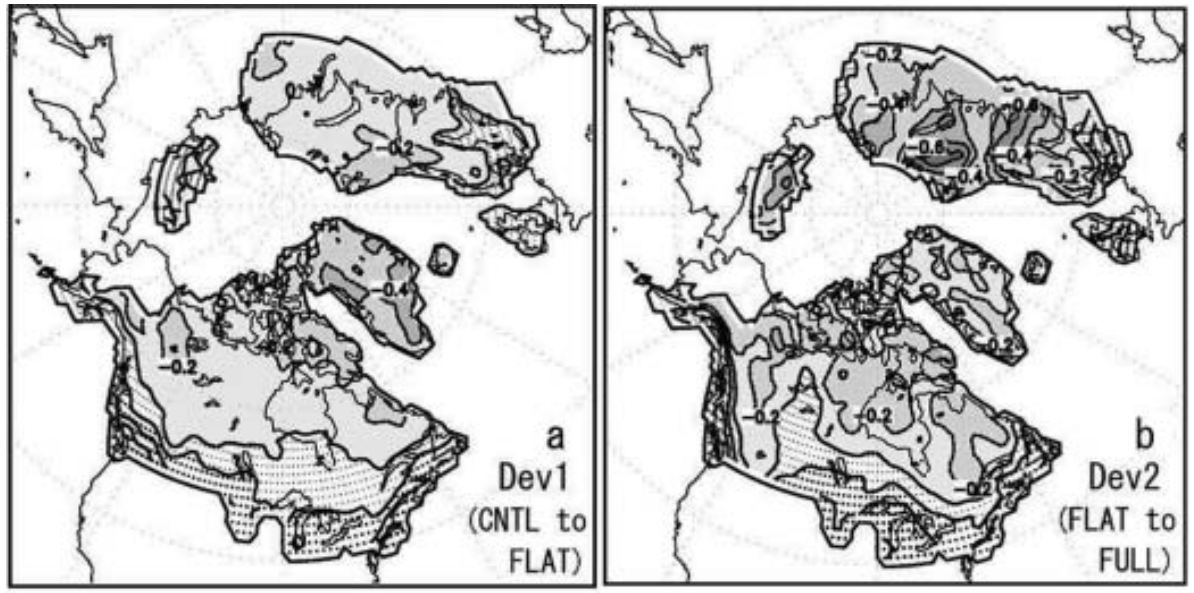

Fig. 6. $(a, b)$ Deviation of the ratio of the precipitation change from CNTL to FLAT and from FLAT to FULL, from the regression curve of the change from CNTL to FLAT and the change from FLAT to FULL, respectively. Contour interval is 0.2 . Negative values are shaded, and positive values are dotted. 


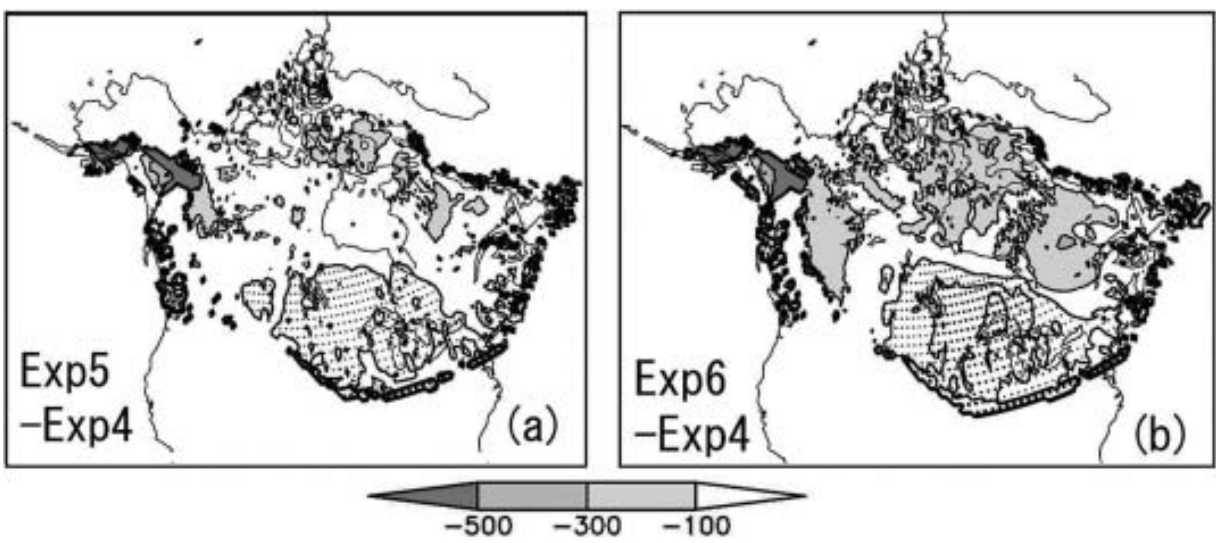

Fig. 7. Difference in topography of the ice surface $(\mathrm{m})(\mathrm{a})$ between Exp5 and Exp4, and (b) between Exp6 and Exp4. Contour interval is $200 \mathrm{~m}$. Shaded values are $<-100 \mathrm{~m}$, and dotted values are $>100 \mathrm{~m}$. Positive values denote smaller results for Exp4.

The last factor contributing to the difference between these simulations is the seasonality of the rate of precipitation change. The AGCM results indicate that the rate changes seasonally by about $3 \% \mathrm{~K}^{-1}$ (Fig. 8), with lower values in summer. Both the seasonal changes show two peaks in spring and late autumn. Considering the yellow and red curves in Figure 8 which show the effect of the seasonal change of precipitation, the two peaks of CNTL to FLAT are mainly due to the seasonal change of precipitation, and those of FLAT to FULL are due to the effect of surface air temperature and precipitation change. Since the seasonality of the rate is derived from the combined effect of surface temperature and precipitation, more prudent and detailed argument is required.

As the parameterization uses the annual mean rate for every month, the large summer precipitation is underestimated. As a result, the parameterized annual precipitation becomes smaller than the AGCM result, and the volume of the steady-state Laurentide ice sheet is underestimated compared to the AGCM result (Exp4). Figure 5 shows that the annual precipitation is higher than the annual mean rate $\left(1.7 \% \mathrm{~K}^{-1}\right.$ and $\left.5.3 \% \mathrm{~K}^{-1}\right)$ when the monthly rates are adopted. This increase compensates for the difference between the precipitation of the AGCM and that parameterized using the annual mean rate $\left(1.7 \% \mathrm{~K}^{-1}\right.$ and $\left.5.3 \% \mathrm{~K}^{-1}\right)$ when the regional variation is taken into account $\left(\operatorname{Dev}_{1}\right.$ and $\left.\operatorname{Dev}_{2}\right)$. The ice-sheet volume in Exp8, which employs the seasonally varying rate, is close to that of Exp3.

\section{SUMMARY AND DISCUSSION}

In the present work, the change in precipitation due to the effects of ice sheets and other factors at the LGM were simulated through AGCM experiments using different boundary conditions. As in previous studies, the coefficients of a parameterization with respect to surface temperature were estimated. The steady-state Laurentide ice sheet was also simulated using a 3-D ice-sheet model, and the precipitation was estimated from different parameterizations and the AGCM result. It was found that the annual precipitation averaged over the Laurentide ice sheet, estimated by a parameterization using the rate determined by the AGCM, is much smaller than that predicted by the AGCM FULL experiment, leading to an underestimation of the volume of the steady-state Laurentide ice sheet. Furthermore, the ratio of precipitation change was found to depend on the location of the ice sheets, indicating that ice-core data such as those of Vostok, Antarctica, and GRIP and GISP, Greenland, cannot be applied to other ice sheets such as the Laurentide and Scandinavian ice sheets. By separating the influences on precipitation over the Laurentide ice sheet into two parts, the ratio of precipitation change unrelated to surface elevation change was found to be $1.7 \% \mathrm{~K}^{-1}$, while the rate due directly to elevation change is $5.3 \% \mathrm{~K}^{-1}$. This difference can be attributed to interior desertification as a result of ice-sheet topography.

The regionality of the rate of precipitation change, due to factors such as interior desertification and the concentration of storm tracks and which is not considered in the conventional parameterization, was found to increase the annual precipitation. Although this result does not affect the estimated steady-state volume of the Laurentide ice sheet, it does have a larger influence on the ice-sheet topography compared to the other effects. This regionality promotes the southward advance of the Laurentide ice sheet at the LGM, and is therefore important when discussing the growth and maintenance of the Laurentide ice sheet. The rate was also shown to change seasonally by about $3 \% \mathrm{~K}^{-1}$ based on the AGCM experiments. This seasonal variation is not considered in the conventional parameterizations, which adopt the annual mean rate for every month, resulting in an underestimation of summer precipitation and hence underestimation of the annual precipitation and ice-sheet volume. As it is difficult to express such seasonal and regional

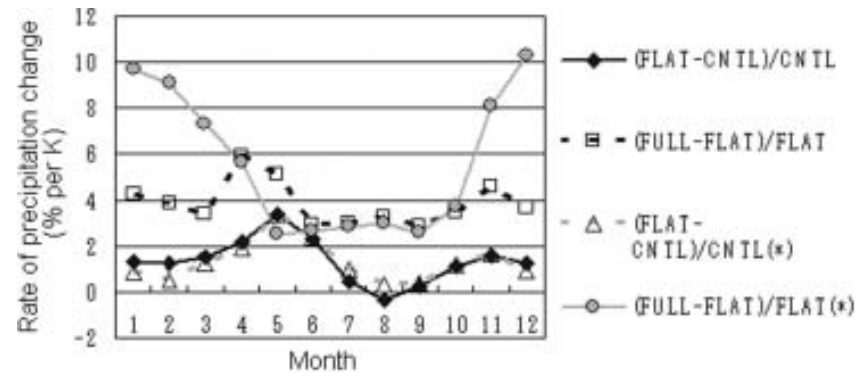

Fig. 8. Seasonal variation in the rate of change from: CNTL to FLAT (solid curve with closed diamond); FLAT to FULL (dashed curve with open square); CNTL to FLAT with annual mean surface temperature (dashed curve with open triangle); and FLAT to FULL with annual mean surface temperature (solid curve with closed circle). 
variations in the rate of precipitation change by a conventional parameterization defined in reference to surface temperature, the authors suggest, based on the present results, that an AGCM should be asynchronously coupled with the ice-sheet model (Charbit and others, 2002), or that a range of uncertainty should be assumed for the rate of precipitation change.

\section{ACKNOWLEDGEMENTS}

We thank D. Dahl-Jensen (Scientific Editor) and two reviewers for their useful and thoughtful comments.

\section{REFERENCES}

Broccoli, A.J. and S. Manabe. 1987. The influence of continental ice, atmospheric $\mathrm{CO}_{2}$, and land albedo on the climate of the last glacial maximum. Climate Dyn., 1(2), 87-99.

Budd, W.F. and I.N. Smith. 1981. The growth and retreat of ice sheets in response to orbital radiation changes. In Sea Level, Ice and Climatic Change. Wallingford, Oxon., International Association of Hydrological Sciences, 369-409. (IAHS Publication 131.)

Charbit, S., C. Ritz and G. Ramstein. 2002. Simulations of Northern Hemisphere ice-sheet retreat: sensitivity to physical mechanisms involved during the last deglaciation. Quat. Sci. Rev., 21(1-3), 243-265.

Clausen, H.B., N.S. Gundestrup, S.J. Johnsen, R. Bindschadler and J. Zwally. 1988. Glaciological investigations in the Crête area, central Greenland: a search for a new deep-drilling site. Ann. Glaciol., 10, 10-15.

CLIMAP Project Members. 1981. Seasonal reconstructions of the Earth's surface at the last glacial maximum. Boulder, CO, Geological Society of America. (Map MC-36.)

Cuffey, K.M. and S.J. Marshall. 2000. Substantial contribution to sea-level rise during the last interglacial from the Greenland ice sheet. Nature, 404(6778), 591-593.

Dansgaard, W. and 10 others. 1993. Evidence for general instability of past climate from a 250-kyr ice-core record. Nature, 364(6434), 218-220.

Fabre, A., G. Ramstein, C. Ritz, S. Pinot and N. Fournier. 1998. Coupling an AGCM with an ISM to investigate the ice sheets mass balance at the Last Glacial Maximum. Geophys. Res. Lett., 25(4), 531-534.

Greve, R., K.H. Wyrwoll and A. Eisenhauer. 1999. Deglaciation of the Northern Hemisphere at the onset of the Eemian and Holocene. Ann. Glaciol., 28, 1-8.

Hall, N.M.J., P.J. Valdes and B. Dong. 1996. The maintenance of the last great ice sheets: a UGAMP GCM study. J. Climate, 9(5), 1004-1019.

Huybrechts, P. and S. T'siobbel. 1995. Thermomechanical modelling of Northern Hemisphere ice sheets with a two-level massbalance parameterization. Ann. Glaciol., 21, 111-116.

Jóhannessen, T., O. Sigurdsson, T. Laumann and M. Kennett. 1995. Degree-day glacier mass-balance modelling with applications to glaciers in Iceland, Norway and Greenland. J. Glaciol. 41(138), 345-358.

Joussaume, S. and K. Taylor. 1995. Status of the paleoclimate modeling intercomparison project (PMIP). In WCRP-2, First International AMIP Scientific Conference, 15-19 May 1995, Monterey, CA. Proceedings. Geneva, World Meteorological Organisation. World Climate Research Programme, 415-430.
Kageyama, M. and P.J. Valdes. 2000. Impact of the North American ice-sheet orography on the Last Glacial Maximum eddies and snowfall. Geophys. Res. Lett., 27, 1515-1518.

Krinner, G. and C. Genthon. 1999. Altitude dependence of the ice sheet surface climate. Geophys. Res. Lett., 26(15), 2227-2230.

Marshall, S.J., T.S. James and G.K.C. Clarke. 2002. North American Ice Sheet reconstructions at the Last Glacial Maximum. Quat. Sci. Rev., 21, 175-192.

National Geophysical Data Center (NGDC). 1988. Data Management Information System - NOAA product information catalog. Washington, DC, US Department of Commerce.

Numaguti, A., T. Takahashi, T. Nakajima and A. Sumi. 1997. Description of CCSR/NIES atmospheric general circulation model. CGER's Supercomputer Monograph Report. Vol. 3. Tokyo, National Institute for Environmental Studies. Center for Global Environmental Research, 1-47.

Peltier, W.R. 1994. Ice age paleotopography. Science, 265(5169), 195-201.

Peltier, W.R. and S. Marshall. 1995. Coupled energy-balance/icesheet model simulations of the glacial cycle: a possible connection between terminations and terrigenous dust. J. Geophys. Res., 100(D7), 14,269-14,289.

Pollard, D. and PMIP Participating Group. 2000. Comparisons of ice sheet surface mass budgets from Paleoclimate Modeling Intercomparison Project (PMIP) simulations. Global Planet. Change, 24(2), 79-106.

Ritz, C., A. Fabre and A. Letréguilly. 1997. Sensitivity of a Greenland ice sheet model to ice flow and ablation parameters: consequences for the evolution through the last glacial cycle. Climate Dyn., 13(1), 11-24.

Roe, G.H. 2002. Modeling precipitation over ice sheets: an assessment using Greenland. J. Glaciol., 48(160), 70-80.

Roe, G.H. and R.S. Lindzen. 2001. The mutual interaction between continental-scale ice sheets and atmospheric stationary waves. J. Climate, 14(7), 1450-1465.

Saito, F. 2002. Development of a three dimensional ice sheet model for numerical studies of Antarctic and Greenland ice sheet. Tokyo, University of Tokyo. Center for Climate System Research. (CCSR Report 15.)

Saito, F. and A. Abe-Ouchi. 2004. Thermal structure of Dome Fuji and East Dronning Maud Land, Antarctica, simulated by a threedimensional ice-sheet model. Ann. Glaciol., 39, 433-438.

Sanberg, J.A.M. and J. Oerlemans. 1983. Modelling of Pleistocene European ice sheets: the effect of upslope precipitation. Geologie en Mijnbouw, 62(2), 267-273.

Tarasov, L. and W.R. Peltier. 1997. Terminating the $100 \mathrm{kyr}$ ice age cycle. J. Geophys. Res., 102(D18), 21,665-21,693.

Tarasov, L. and W.R. Peltier. 2004. A geophysically constrained large ensemble analysis of the deglacial history of the North American ice sheet complex. Quat. Sci. Rev., 23, 359-388.

Vettoretti, G., W.R. Peltier and N.A. McFarlane. 2000. Global water balance and atmospheric water vapour transport at Last Glacial Maximum: climate simulations with the Canadian Climate Centre for Modelling and Analysis atmospheric general circulation model. Can. J. Earth Sci., 37(5), 695-723.

Xie, P. and P.A. Arkin. 1996. Analyses of global monthly precipitation using gauge observations, satellite estimates, and numerical model predictions. J. Climate, 9(4), 840-858.

Yiou, F., G.M. Raisbeck, D. Bourles, C. Lorius and N.I. Barkov. 1985. ${ }^{10} \mathrm{Be}$ in ice at Vostok Antarctica during the last climatic cycle. Nature, 316(6029), 616-617.

Zweck, C. and P. Huybrechts. 2003. Modeling the marine extent of Northern Hemisphere ice sheets during the last glacial cycle. Ann. Glaciol., 37, 173-180. 